\title{
$\forall$ \\ INTERCAPILLARY GLOMERULOSCLEROSIS AND THE KIMMELSTIEL-WILSON SYNDROME
}

\author{
By Graham Poole, M.B., M.R.C.P. \\ Senior Registrar, Grove Park Hospital, London; late Sentor Registrar, Queen Elizabeth Hospital, Birmingham
}

Kimmelstiel and Wilson in 1936 described a clinico-pathological syndrome characterized by hypertension, renal failure with albuminuria, widespread oedema and retinitis in longstanding and often mild diabetics whose kidneys demonstrated histologically what they termed intercapillary glomerulosclerosis. It is the purpose of this article to stress again the frequency of this grave complication of diabetes, more especially because it affords opportunity to emphasize the degree to which the smallest divisions of the vascular tree may be involved in grossly pathological processes in diabetic subjects, also to attempt to clarify the position of intercapillary glomerulosclerosis and the Kimmelstiel-Wilson syndrome.

In the United States in 1943 diabetes mellitus ranked eighth on the list of causes of death, accounting for one in 40 of deaths from all causes (Joslin, 1946). There has been a world-wide increase in the average age at death, due largely to insulin. In Toronto the average age in I9I4 was 45.3, whereas in 1945 it was 66.5. Even so, diabetes is not a disease of old age; the maximum susceptibility is at $5^{\mathrm{I}}$ years for males and 55 years for females. Lawrence estimated in 1939 that there were 150,000 to 200,000 diabetics in the United Kingdom. With regard to sex, Joslin states that until the age of 25 there is no significant difference, but from then onwards there is a predominance of female diabetics, so that at the age of 65 one in 45 women is diabetic as compared with one in 70 men. The death rates per 100,000, in most countries, for females exceed those for males by 25 per cent. or more. In an analysis of causes of death in 8,384 diabetics the Statistical Bureau of the Metropolitan Life Insurance Company found that 67.4 per cent. were due to lesions of the cardio-renal-vascular systems; in 66.6 per cent. marked arteriosclerosis was present. Root and Sharkey (1936) demonstrated that excessive development of arteriosclerosis followed the onset of diabetes.
It is clear, therefore, that if the average age at death is to be further increased every effort must be made to minimize those factors which accelerate vascular disease or ageing.

Interest was stimulated when during the course $\vec{\omega}$ of the period September 1947 to March 1949, three $\vec{v}$ women were admitted to and died in Hallam 은 Hospital, West Bromwich, all conforming pre- $\vec{r}$ cisely to the pattern of the cases originally described by Kimmelstiel and Wilson.

\section{Case Report I}

Female, aged 53 years, admitted on January I 1949.

History. Ten years before admission the patient developed malaise, loss of weight, polyuria, polydipsia and pruritus vulvae; a diagnosis of diabetes was made and she was treated with diet, apparently $\mathbb{D}$ satisfactorily, for her weight remained constant and there were no diabetic symptoms. Two years before admission oedema developed quite suddenly and persisted for one to two months; no investigations were made at that time. From then onwards, however, a steadily increasing dyspnoea developed which became very marked two to three months before admission following an attack of bronchitis. Immediately after the attack of bronchitis oedema developed again and persisted. For one year before admission there had been steadily failing vision. At the time of admission the patient was orthopnoeic, obese and had a pale, bloated appearance. There was marked oedema of legs, abdominal wall and sacral region. The pulse rate was 76 and regular; blood pressure was 180/108; the apex beat was in the anterior axillary line and there was presystolic triple rhythm. Ophthalmoscopic examination showed a vitreous haemorrhage in each eye, and although the left fundus was somewhat obscured by the haemorrhage it seemed probable that there was a retinal detachment. The picture, however, was one mainly of venous distension and developing 
oedema of the retinae. The arteries were not grossly abnormal. Several exudates were seen on the right side and on the left side several small aneurysmal dilatations of the types described by Ballantyne were present above and temporal to the disc.

The patient required I 4 units of protamine zinc insulin daily and was also treated with digoxin and diuretics. The signs persisted and the patient died.

Post-mortem examination showed some ascites and bilateral pleural effusions, the lungs were normal. The pericardium was normal but there was gross hypertrophy of the myocardium, the heart weighing I4 oz. There was widespread arteriosclerosis. The right kidney weighed $5 \frac{3}{4} \mathrm{oz}$. and the left $6 \frac{3}{4} \mathrm{oz}$., both were pale with some loss of cortical pattern and narrowing of the cortex; the capsules were adherent; the renal vessels were markedly arteriosclerotic.

\section{Case Report 2}

Female, aged 46 years, admitted on October 7 , 1947.

History. For six months there had been a history of rapidly failing vision; four months before admission she had attended a local eye hospital where a diagnosis of diabetes was made

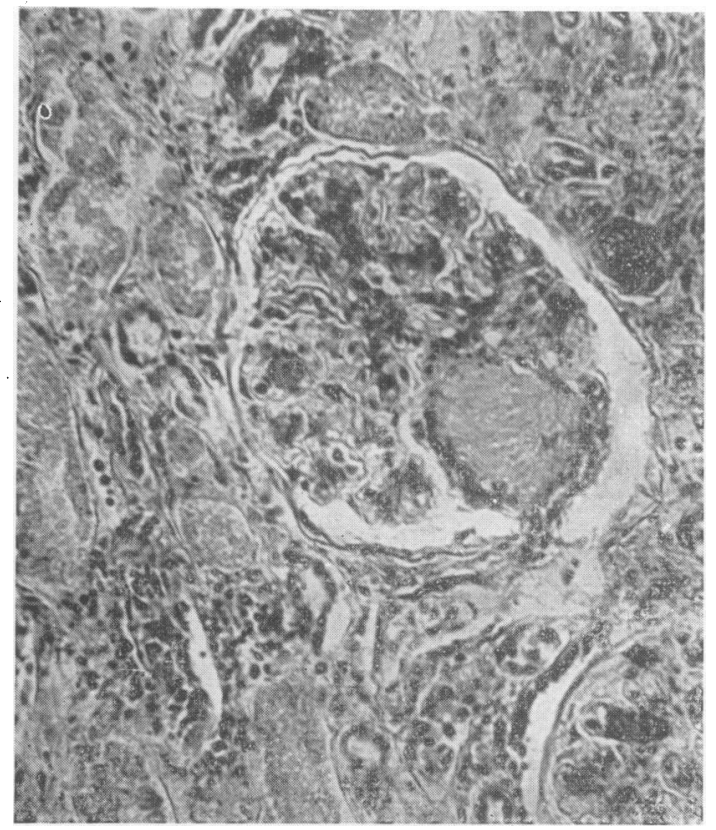

FIG. 1.-(Case No, 2.) Large rounded hyaline mass in the glomerulus. H. and E. $\times 220$. and treatment with insulin commenced. Concomitant with the failing vision the patient had become short of breath and more recently had developed a persistent cough productive of a little purulent sputum daily. Three weeks before admission oedema developed and quickly became widespread, involving the feet, legs, abdomen, trunk, face and hands. At the time of admission the patient was almost blind, she was grossly bloated with oedema of the hands, arms, feet, legs, abdominal wall and back. On examination of the cardiovascular system the pulse rate was 80 and regular, the blood pressure was $212 / 128$; on auscultation a presystolic triple rhythm was noted. Examination of the eyes showed bilateral subacute congestive glaucoma. It was almost impossible to obtain a satisfactory view of the fundi, but on the left there were evident haemorrhages and exudates. Small bilateral pleural effusions were found and there were moist sounds above the effusions posteriorly on both sides. Ascites was present.

The patient died five weeks after admission, and during the period in hospital had not required insulin.

Post-mortem examination revealed small bilateral pleural effusions and pulmonary oedema. There was hypertrophy of the myocardium with fibrotico scarring of the interventricular septum below the aortic valve, having the appearance of myocardialo infarction. A moderate amount of free fluid was

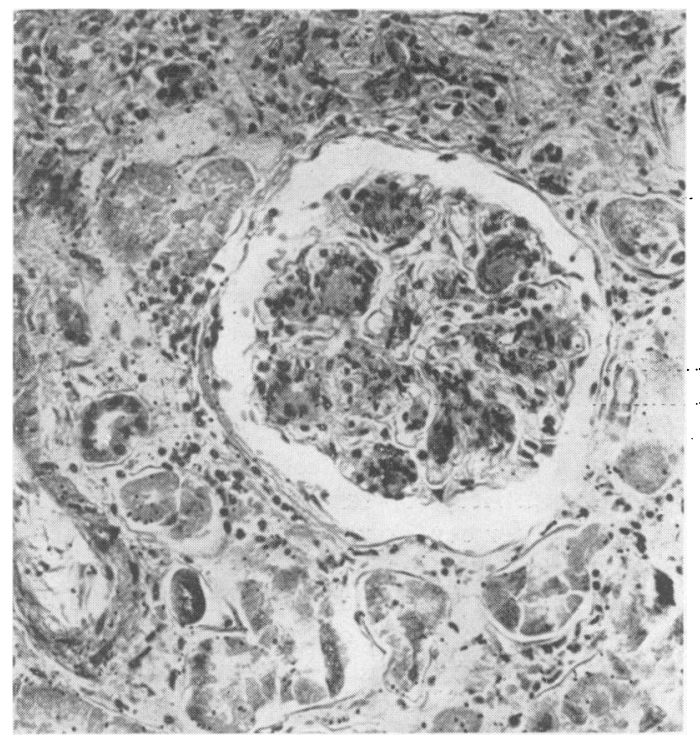

FIG. 2.-(Case No. r.) Several hyaline masses developing in the glomerulus. H. and E. $\times 220$. 
found in the abdomen. Macroscopic examination of the kidneys revealed several cortical abscesses in each. A general fairly severe arteriosclerosis was present. Pathological sections of an eye showed marked degeneration of the retina with haemorrhages and exudates; there was considerable distension of the retinal veins. See Fig. 7 .

\section{Case Report 3}

Female, aged 60 years, admitted on January 28, 1948.

History. There was a history of over five years' diabetes treated with insulin but very erratically, largely because of the patient's defection. Otherwise the patient had been well and in apparently normal health until seven to eight months before admission, when swelling of the legs developed at first only at night time but rapidly became persistent and more general. The patient was admitted with a right hemiplegia and aphasia. The pulse rate was 88 and regular; the blood pressure was $168 / 88$; there was marked oedema of the feet, legs, abdominal wall, sacral region and arms. Examination of the fundi showed moderate arteriosclerosis, several recent exudates and haemorrhages, and in both eyes on the temporal side of the disc were several diabetic aneurysms. Rales were heard over both lower lobes posteriorly. During the patient's stay in hospital insulin was

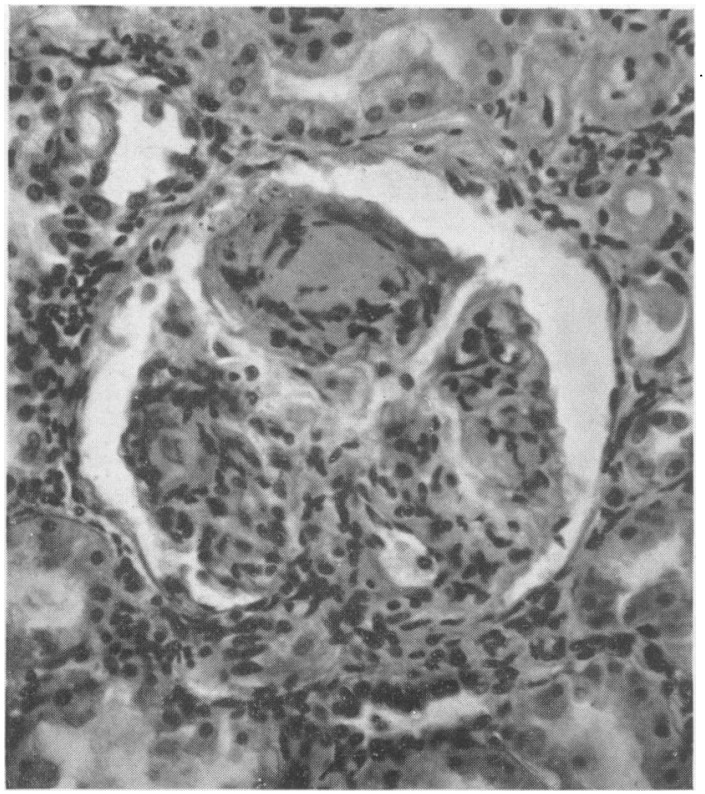

FIG. 3.-(Case No. 3.) Peripheral mass with second smaller one. H. and E. $\times 300$. not required. The patient died of bronchopneumonia two months after admission.

Post-mortem examination. In the lungs there were widespread broncho-pneumonic changes. There was hypertrophy of the myocardium, especially of the left ventricle; the heart weighing $1 \mathrm{I}$ oz. The right kidney weighed $7 \frac{1}{2} \mathrm{oz}$. and the left $5 \frac{3}{4}$ oz.; there were two small cortical abscesses on the right side and one on the left. The renal vessels were very arteriosclerotic.

\section{Discussion}

The following discussion is based upon an extensive review of the literature; where figures are quoted these refer only to cases of the KimmelstielWilson syndrome described in detail and upon which autopsy was subsequently performed. The variations in figures quoted is the result of varying information given by different authors.

I. Diabetes. The average duration in 84 autopsied patients was ro years; generally speaking the diabetes was not severe; between onethird and one-half of the cases at the time of their last admission to hospital were controlled by diet alone, and no more than a quarter of the cases required over 20 units of insulin per day. Martin observed that, in some cases, with the progress of the renal lesion a steady decrease in the severity of the diabetes took place as judged by insulin re-

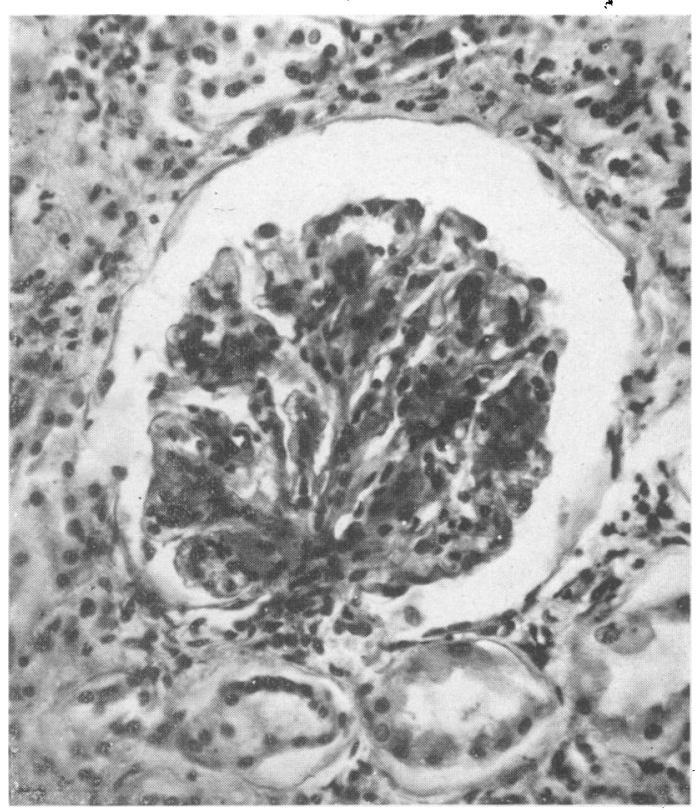

Fig. 4.-(Case No. 2.) Difiuse sclerosis of the glomerulus. H. and E. $\times 300$. 
'TABLE I

LABORATORY INVESTIGATIONS

\begin{tabular}{|c|c|c|c|}
\hline Case & (I) & (2) & (3) \\
\hline $\begin{array}{c}\text { URINE- Specific Grafity } \\
\text { Albumen } \\
\text { Sugar } \\
\text { Deposit }\end{array}$ & $\begin{array}{l}\text { IOI } 5 \\
++0.2-0.5 \% \\
+\quad \text { R.B.C. } \\
\text { No R.B.C. } \\
\text { Occ. Hy. and G. casts }\end{array}$ & $\begin{array}{l}\text { I010-10I5 } \\
++0.2-0.5 \% \\
+++ \\
\text { Nil } \\
\text { Later B. Coli and Pus }+\end{array}$ & $\begin{array}{l}1012 \\
++0.5 \% \\
\text { Nil } \\
\text { Pus }+ \\
\text { Few R.B.C.s } \\
\text { No casts } \\
\text { Later Staph. aureus }\end{array}$ \\
\hline $\begin{array}{c}\text { BLOOD-Haemoglobin } \\
\text { Red Blood Cells } \\
\text { White Blood Cells } \\
\text { E.S.R. (Westergren) }\end{array}$ & $\begin{array}{l}82 \% \\
4,210,000\end{array}$ & $\begin{array}{l}100 \% \\
5,200,000 \\
10,900 \\
29 \mathrm{~mm} . \text { Ist hr. }\end{array}$ & $\begin{array}{l}96 \% \\
4,800,000 \\
\text { II,200 } \\
21 \mathrm{~mm} . \text { ist hr. }\end{array}$ \\
\hline PLASMA PROTEINS-Gr. $\%$ & $5.5 \begin{cases}A & 3.0 \\
G & 2.5\end{cases}$ & $5.35 \begin{cases}A & 2.1 \\
G & 3.25\end{cases}$ & $5.0 \begin{cases}A & 1.8 \\
G & 3.2\end{cases}$ \\
\hline $\begin{array}{c}\text { G.T.T.-Fasting Blood Sugar } \\
\text { Maximum } \\
\text { At } 120 \mathrm{~min} .\end{array}$ & $\begin{array}{l}\text { I } 30 \mathrm{mgm} . \% \\
\text { 1 } 90 \mathrm{mgm} . \% \\
\text { I } 80 \mathrm{mgm} . \%\end{array}$ & 210 (Fasting B.S.) & I 90 (Fasting B.S.) \\
\hline $\begin{array}{l}\text { UREA-mgm. } \% \\
\text { U.C.T. } \\
\text { CHOLESTEROL-mgm. } \%\end{array}$ & $\begin{array}{l}66 \\
10.5 \mathrm{cc} .-20 \% \\
270\end{array}$ & $\begin{array}{l}55 \\
\text { I } 4 \text { cc. }-26 \% \\
\text { I } 76\end{array}$ & $\begin{array}{r}90 \\
255\end{array}$ \\
\hline BLOOD PRESSURE & I 80/108 & $212 / 128$ & $168 / 88$ \\
\hline
\end{tabular}

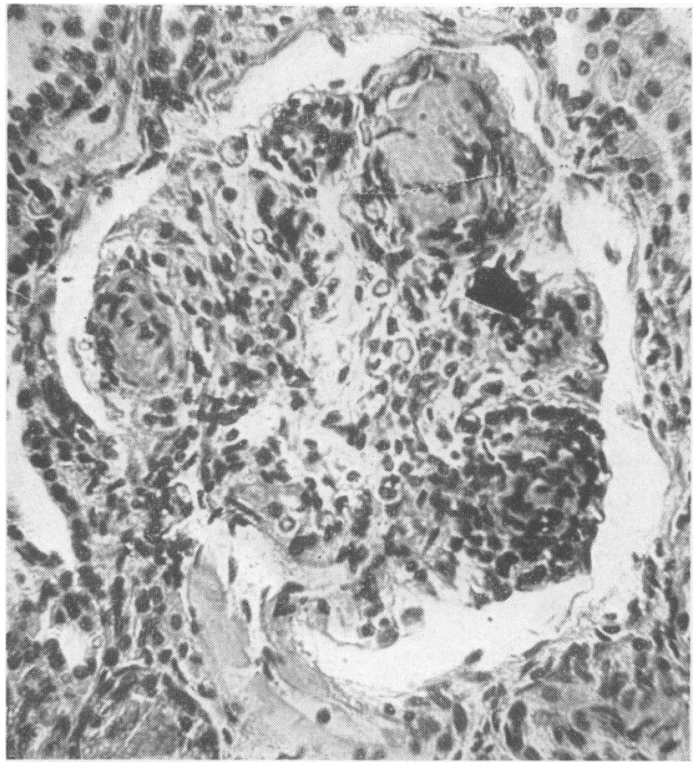

FIG. 5.-(Case No. 1.) Marked hyaline change in arteriole-peripheral mass. $H$. and $E$.

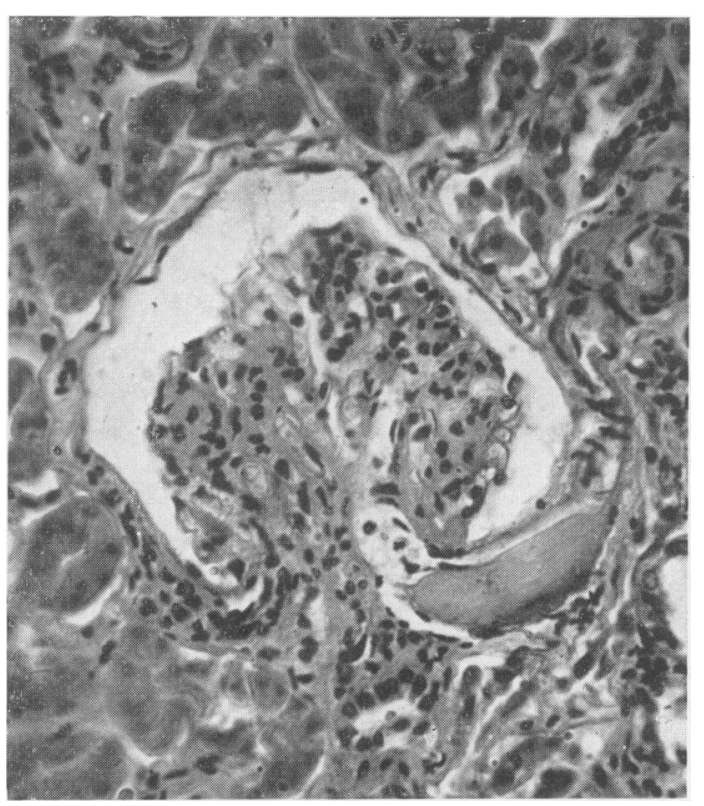

FIg. 6.-(Case No. 3.) Gross hyaline change in efferent arteriole with diffuse sclerosis. $H$. and E. $\times 300$. 
quirements, blood sugar and glycosuria. Zubrod et al. (195I) have studied the apparent amelioration of diabetes in patients with the KimmelstielWilson syndrome and concluded that the rarity of diabetic acidosis is so striking that it provides a clue during life to the presence of KimmelstielWilson lesions. The same authors (1952) have shown that insulin can be withdrawn without the development of acidosis in these cases. Root et al. (1950) state in a review of 282 diabetics that renal lesions developed in $5 \mathrm{I}$, but only in five of these did they begin before the tenth year of diabetes. They also state that inter-capillary glomerulosclerosis is more malignant in young diabetics of long duration than in later life and is, therefore, related to the severity of the diabetes.

2. Age and sex. Of I 10 cases reviewed in the literature, 72 were women and 38 men, the average age of the women was 57.3 and of the men 56.7 ; only eight of the cases were below 40 years of age.

3. Renal pathology. On naked eye examination there is no characteristic change, and the weight of the kidneys has varied from 90 to $250 \mathrm{~g}$.; there has in almost all of the cases been evident arteriosclerosis, but usually with surprisingly little contraction or granularity.

Microphotographs illustrate the appearances seen histologically. In typical cases two features are especially prominent; (i) there is a severe arteriosclerosis and arteriolosclerosis, in particular the efferent and the afferent vessels of the glomeruli are frequently the site of a gross hyaline thickening; this involvement of the efferent vessels Allen regards as peculiar to these diabetic cases; (ii) in the glomeruli themselves one finds rounded, homogenous, acidophile, peripherally placed deposits, but in other cases a diffuse infiltration of the tuft with a similar hyaline material. The condition is distinct from amyloid disease since the hyaline deposit does not give the characteristic staining reactions obtained in amyloid disease.

The severity of the glomerular lesions is closely related to the degree of arteriosclerosis (Allen, 1941). The sclerosis of the small renal vessels results from a subintimal deposit of hyaline material (Bell). While these changes may be present in normotensive patients they are more marked when there is a concomitant hypertension (Bell).

With regard to the glomerular lesion four degrees of severity have been described by Laipply et al. (i) Focal fibrosis with spherical masses, usually similar bilaterally. (ii) Only an occasional spherical mass. (iii) Spherical masses in many glomeruli. (iv) One or two spherical masses in nearly all glomeruli. The particular points of interest in the glomerular lesion are that on examination with a higher power the hyaline deposits are seen to be laminated (this, according to Allen, is best shown by means of silver stain), and unlike hyaline deposit in non-diabetic subjects they are found to occur in the periphery of the capillary tuft. With increase in size they displace the adjacent capillaries outwards and patent capillaries may often be seen at the circumference of the mass. It has been suggested that the hyaline deposits are rounded because of the pressure from surrounding capillaries (Gunter).

The origin of the rounded deposits is debated. Kimmelstiel and Wilson, following MacCallum, believe that there may be a third glomerular element or intercapillary connective tissue (mesangium of lower animals) from which the hyaline tissue is derived. Allen and Bell on the other hand consider that the intercapillary masses are derived from the capillary wall, in particular from the splitting of their inner basement membranes, and hold the more commonly accepted view that there is no connective tissue element between the capillaries peripherally. MacManus, who has studied renal diabetic lesions with the periodic acid Schiff's reagent method which demonstrates especially glomerular basement membranes, considers that there is an external, but not an internal basement membrane, and he considers that the hyaline masses are deposited from the capillaries into the intercapillary space.

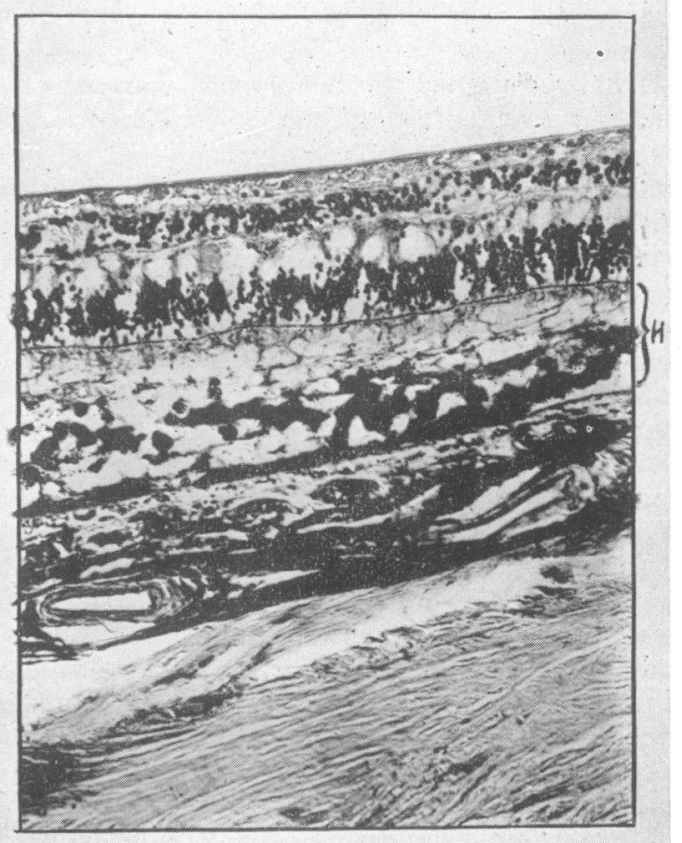

Fig. 7.-(Case No. 2.) Retina showing haemorrhage, $\mathrm{H}, \times 125$. 
TABle 2

\begin{tabular}{|c|c|c|c|c|c|c|c|c|c|c|c|c|}
\hline & \multicolumn{3}{|c|}{ Diabetics } & \multicolumn{3}{|c|}{$\begin{array}{c}\text { Arteriolo- } \\
\text { Nephrosclerosis }\end{array}$} & \multicolumn{3}{|c|}{$\begin{array}{l}\text { Glomerulo- } \\
\text { Nephritis }\end{array}$} & \multicolumn{3}{|c|}{$\begin{array}{l}\text { Pyelo- } \\
\text { Nephritis }\end{array}$} \\
\hline & $\begin{array}{l}\text { Total } \\
\text { Cases }\end{array}$ & $\begin{array}{l}\text { No. } \\
\text { with } \\
\text { I.G.* }\end{array}$ & $\begin{array}{l}\text { Per } \\
\text { * Cent. }\end{array}$ & $\begin{array}{l}\text { Total } \\
\text { Cases }\end{array}$ & $\begin{array}{l}\text { No. } \\
\text { with } \\
\text { I.G. }\end{array}$ & $\begin{array}{l}\text { Per } \\
\text { Cent. }\end{array}$ & $\begin{array}{l}\text { Total } \\
\text { Cases }\end{array}$ & $\begin{array}{l}\text { No. } \\
\text { with } \\
\text { I.G. }\end{array}$ & $\begin{array}{l}\text { Per } \\
\text { Cent. }\end{array}$ & $\begin{array}{l}\text { Total } \\
\text { Cases }\end{array}$ & $\begin{array}{l}\text { No. } \\
\text { with } \\
\text { I.G. }\end{array}$ & $\begin{array}{l}\text { Per } \\
\text { Cent. }\end{array}$ \\
\hline $\begin{array}{l}\text { Horn and Smetana } \\
\text { Laipply et al. } \\
\text { Bell }\end{array}$ & $\begin{array}{l}126 \\
124 \\
460\end{array}$ & $\begin{array}{r}33 \\
79 \\
\mathbf{1} 15 \\
\end{array}$ & $\begin{array}{l}26.2 \\
63 \cdot 7 \\
25\end{array}$ & $\begin{array}{l}\mathrm{I} 44 \\
\mathrm{I} 24 \\
-\end{array}$ & $\begin{array}{r}32 \\
\mathrm{I} \\
-\end{array}$ & $\begin{array}{r}22.2 \\
0.8 \\
\end{array}$ & $\begin{array}{r}199 \\
24 \\
-\end{array}$ & $\begin{array}{r}13 \\
3 \\
-\end{array}$ & $\begin{array}{r}6.5 \\
125 \\
-\end{array}$ & $\overline{60}$ & $\underline{-}$ & $\overline{1.7}$ \\
\hline
\end{tabular}

* Intercapillary Glomerulosclerosis

4. Frequency and specificity of the renal lesion. Allen examined the kidneys from 105 consecutive patients with diabetes, Ioo consecutive patients without diabetes but with hyperiension, Ioo nondiabetic non-hypertensive patients and 34 patients with glomerular nephritis. He found some degree of intercapillary glomerular sclerosis in 33 per cent. of diabetic patients over 40 years; in the control groups only one patient showed intercapillary glomerulosclerosis. Table 2 shows the results of other investigators assessing the frequency with which intercapillary glomerulosclerosis occurs in various conditions.

In an excellent paper on this subject Gilliland (195I) investigated the necropsy records of $4^{6}$ diabetics and correlated the pathological findings with the recorded clinical conditions. He found the typical nodular lesion in I I cases of which ro were women.

I have examined the histological material of 25 diabetic patients (average age $5^{6}$ ), 50 hypertensive patients with nephrosclerosis and 20 chronic nephritic patients. Among diabetics I found three with nodular form, four with diffuse form and 18 with apparently normal kidneys. Among chronic nephritics no kidneys showed the typical nodular form of intercapillary glomerulosclerosis, and in hypertensive cases seven showed a diffuse intercapillary glomerulosclerosis but none present a typical nodular type of lesion. In the material examined there was frequent evidence of concomitant pyelonephritis, a finding noted by Wilson et al.

In a later review of the subject, Kimmelstiel and Porter point out that the original pathological descriptions of Kimmelstiel and Wilson referred only to the nodular type of lesion. 'They consider that the diffuse type of lesion is not at all specific and that its inclusion by some authors accounts for the high proportion of cases of intercapillary glomerulosclerosis sometimes stated to occur'both in diabetics and non-diabetics. Kimmelstiel and Porter believe that the nodular type of lesion occurs in about 17 per cent, of all diabetic cases, is most frequent in the sixth decade $\stackrel{\rho}{\omega}$ and is twice as common in the female sex.

One may conclude that while the nodular form 3 of intercapillary glomerulosclerosis may occur very infrequently apart from diabetes the severe forms $\omega_{\text {}}$ are always associated with diabetes, so much so $\mathcal{C}_{0}$ that a number of authors (Laipply, Eitzan and $\vec{\omega}$ Dutra, 1944) have considered that it is the most reliable post mortem means of assessing whether a 을 patient may have had diabetes.

5. Differentiation of the renal lesion. 'The distinction from cases of chronic glomerular nephritis may be difficult, and it should be said that the two $\triangle$ processes are not exclusive. Points of difference, $\vec{\theta}$ however, are that the capillary basement merec brane in glomerular nephritis (inflammatożं lesions) is split and wrinkled (Allen, I94I ; Herbut, I941) whereas in degenerative lesions, e.g. intercapillary glomerulosclerosis, it is not; crescent forms are uncommon in intercapillary sclerosis, $\frac{\Omega}{\mathbb{Q}}$ and there is much more uniformity in the size of the lesions in intercapillary sclerosis than in glomerulo nephritis. One of the most important $\frac{3}{5}$ differences is that the intercapillary lesions are usually accompanied by a hyaline efferent arteriole. In the material examined chronic glomerulo- $\frac{3}{3}$ nephritis produces a more gross change with many more glomeruli wholly destroyed, there is much 3 . more capsular reaction and more interstitial reaction. 'Thus, though individual glomeruli may appear very like those seen in intercapillaryo glomerulosclerosis, the whole section is not likely to be confused. Amyloid iodine tests and othero specific stains are negative in intercapillary glomerulosclerosis. In nephrosclerosis the afferent 0 and efferent glomerular arterioles do not shown hyaline thickening so regularly as in diabetic inter-N capillary glomerulosclerosis. But more important, $\frac{\omega}{\sigma}$ whereas the hyaline masses in intercapillary glomerulosclerosis are located peripherally, in nephrosclerosis the intercapillary sclerosis is diffuse and radiates from the hilum (where it occurs maxi- + mally) to the periphery. This type of lesion may be difficult to distinguish from the diffuse lesion $\vec{\nabla}$ 
occurring in diabetics, but it is quite distinct from the nodular intercapillary lesion.

6. Retinitis. In the great majority of cases quoted in the literature some form of retinal pathology was present. In more than 50 per cent. of those where fundal examination is mentioned haemorrhages and/or exudates were discovered. In two of the present cases diabetic aneurysms were present; in all three of them haemorrhages and exudates and some degree of arteriosclerosis. Arteriosclerosis is not essential to the presence of diabetic retinopathy nor even according to Waite and Beetham is it present more frequently in the fundi of those diabetics exhibiting retinal disease than in a control group of normal patients. Dolger considers that the retinopathy is usually the earliest evidence of vascular damage in diabetics and that the changes depend upon the duration of diabetes, so that when it has persisted for 25 years hardly a case will escape retinal haemorrhage. Croom, who investigated 60 cases where diabetes had been present from 15 to 26 years, concluded that retinopathy was not inevitable even after 26 years, that arteriosclerosis and hypertension were not essential to diabetic retinopathy and that the changes were not apparently related to the severity of the diabetes or its control.

7. Hypertension. Of 95 cases reviewed in the literature, the blood pressure was over I60 systolic and/or 90 diastolic in 79 cases, over 100 diastolic in 64 cases and below $160 / 90$ in only 13 cases. Of 60 cases investigated clinically by Seigal and Allen, not all with subsequent postmortem examination, 12 were not hypertensive.

8. Urine. Specific gravity. No definite information is forthcoming from the literature since it is not clear whether albuminuria or glycoscuria have been taken into account.

Albuminuria. Present in all cases, varying from a trace to more than 0.5 per cent.

Deposit. This is only described in detail in a few articles; about one-third of the cases showed occasional hyaline and granular casts.

Red blood cells are infrequently mentioned; in these instances they were absent or occasional.

Pus was present in almost half the cases where mentioned. The frequency of urinary infections is stressed by Gilliland (.195 I).

A somewhat striking feature is the apparently small number of casts commonly seen. 'I'he only detailed examination of deposit was undertaken by Alwell on two of his cases, Addis counts on the urine gave the following results: (i) 5,000 R.B.C., 4,750 W.B.C. and 300 granular casts per 12 hours, and (ii) 5,500 R.B.C. and 148,800 W.B.C. per 12 hours. Addis counts may thus help in distinguishing the condition from glomerulo-nephritis.
9. Oedema. Of 82 cases reviewed, oedema was general in 45 , restricted to the legs and feet in 233 and absent in 14. Undoubtedly the oedema in many cases resulted from congestive cardiace. failure, but laboratory investigations suggest that: in 20 of the above cases the oedema was certainly? in part of the nephrotic type and in 10 more? probably so. Laipply (cases are not quoted in $\frac{\bar{\sigma}}{\bar{s}}$ detail) found the nephrotic syndrome to be $\frac{\text { ? }}{\sigma}$ present in only 6.3 per cent. of 79 cases showing intercapillary glomerulosclerosis. In view of the apparent inclusion by Laipply of many cases not $-\vec{\circ}$ exhibiting the nodular lesion this figure is almost:certainly too low.

Iо. Laboratory investigations. Table 3 summarizes the relevant laboratory investigationso most regularly quoted by the various investigators.

I I. Neuropathy. Few observers have noted the occurrence of neuropathy, but Gilliland (I95I) states that there was more frequent and obviouse reference to peripheral neuropathy in the II cases $\vec{\omega}$ having Kimmelstiel-Wilson lesions than in the other diabetics in his series of 46 cases.

12. Cause of death. In 60 cases reviewed as to $\overrightarrow{7}$ cause of death, death was due in 16 to uraemia, in I 5 to cardiac failure, in I I cases to pneumonia, in four to gangrene, in four to pyogenic infections of the kidney and in ten to a variety of other cause including pulmonary tuberculosis in four cases.

\section{Comment}

Two types of diabetic intercapillary glomerulo- $-\bar{\partial}$ sclerosis occur-diffuse and nodular forms. The diffuse form does not appear to be sufficiently@ well defined to be sure of its close relation to $\Rightarrow$ diabetes. The nodular form originally described 3 by Kimmelstiel and Wilson is histologically a dis-? tinct lesion and occurs, with the possible exceptiono of some cases of chronic glomerulonephritis, onlyo in diabetic subjects. From the clinical point of view cases of chronic glomerulonephritis and inter-capillary glomerulosclerosis exhibit differences (see. Henderson et al., 1947), for example the haemo-ô globin and red blood cell count are markedly lower? in chronic glomerulonephritis and the blood ureao is commonly much higher.

Tnough oedema was present in all of the original Kimmelstiel and Wilson cases leading to their description of the syndrome, many cases of intercapillary glomerulosclerosis will certainly beN found in which oedema has not been present N None the less, a diabetic over 40 years of age with general oedema, especially if there is gross albuminuria, hypoprotinaemia, retinopathy and per $\frac{\text { त }}{\mathbb{D}}$ haps hypercholesterolaemia, may be confidentlys expected to exhibit a moderate or severe degree of intercapillary glomerulosclerosis. In other words,, a severe degree of this will tend to produce 


\begin{tabular}{|c|c|c|c|c|c|c|c|c|c|}
\hline & రั๊ & $m-m m$ & 1 & in 1 & -1 & $m n$ & $+m$ & ก) & \\
\hline \multirow{3}{*}{ 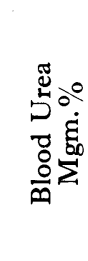 } & F。용 & Nan/min & 1 & 11 & $N e$ & $+n$ & $n a$ & m & \\
\hline & $\frac{3}{0} q$ & $\pi|\sim| \mid-$ & - & $-a$ & -1 & $n$ & $a n$ & 2 & \\
\hline & 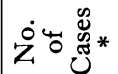 & & - & on & +0 & $\pm n$ & $\pm \infty$ & $\infty$ & \\
\hline \multirow{2}{*}{ 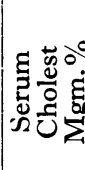 } & 苍品 & $|v|-||$ & 1 & -1 & $1 m$ & $\cong-$ & -1 & $\hat{\sim}$ & \\
\hline & $\dot{0}$ & $|x-m| \mid$ & । & -1 & -+ & $\simeq N$ & 01 & $m$ & \\
\hline \multirow{2}{*}{ 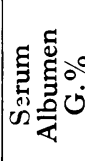 } & 㶽台兽 & $|-||| \mid$ & 1 & |1 & $\sim+$ & in $x$ & 11 & $m$ & \\
\hline & 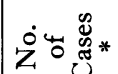 & $|N m-n|$ & - & -1 & + in & an & $1-$ & $\underset{\sim}{\infty}$ & \\
\hline \multirow{6}{*}{$\frac{0}{0}$} & $\mid \begin{array}{l}n \\
\dot{n} \\
\dot{n}\end{array}$ & $|m-m|$ & 1 & N। & $+n$ & $n$ & 01 & 요 & \\
\hline & $\dot{0}$ & $|N M m-|$ & $m \quad$ & N। & + in & $z^{N}$ & $\approx m$ & $\hat{f}$ & 무 \\
\hline & 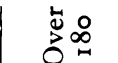 & $m$ int $-\infty$ & - & $m-$ & -0 & $\pm n$ & $t+$ & in & $\mathbb{Z}$ \\
\hline & 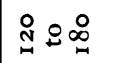 & $\left.|1| 1\right|^{-}$ & 1. & $m$ & $m 1$ & | | & 11 & - & \\
\hline & 莺 。 & $|1||| \mid$ & 10 & N। & 1 1 & 11 & I & + & e \\
\hline & 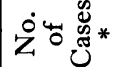 & $m+n+a$ & - & $\mathrm{On}$ & +0 & $\pm N$ & $+\infty$ & 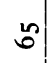 & \\
\hline \multirow{3}{*}{ 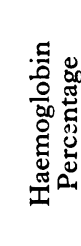 } & 苟。ํำ & ||$N m \mid$ & 1 & $\mid 1$ & $+m$ & N I & $n$ & : & \\
\hline & s: & ||$m|N|$ & 1 & 11 & 11 & On & -1 & i & \\
\hline & $\dot{0}$ & || $\operatorname{mon} \mid$ & 11 & & $+\quad+$ & & \pm 1 & $q$ & \\
\hline \multicolumn{2}{|c|}{ 范 } & \multicolumn{6}{|c|}{ 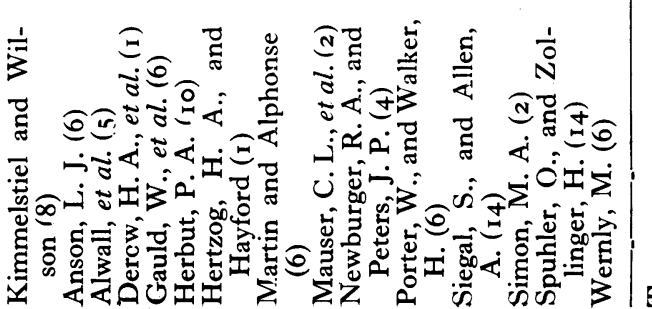 } & & 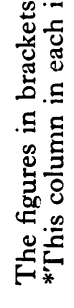 \\
\hline
\end{tabular}


nephrotic picture but a very much later stage than the average Stage 2 glomerular nephritis. Severe and proportional arterio- and arteriolo-sclerosis concomitantly occur with intercapillary glomerulosclerosis. The presence of moderate or severe retinal arteriosclerosis will indicate a more probable finding of intercapillary glomerulosclerosis.

Whilst the investigations of the three authors Oakley, Laipply and Croom all suggest that the control of diabetes is not related to the development of complications or of intercapillary glomerulosclerosis (Horn and Smetana, and Goodof) the most recent and very careful reviews of Root et al. (1950) and Wilson et al. (195 I) indicate that better control results in fewer complications. It seems, therefore, that until there is strong contra-evidence more careful control of diabetes should be resolutely pursued. Other points of decided interest are the observations of many authors on the relation of arteriosclerosis to disordered lipoid and cholesterol metabolism (first suggested by Virchow).

Spuhler and Zollinger (1943) consider that in association with diabetes there is a marked alteration in the permeability of cell membranes leading to abnormal lipoid storage; the same authors consider that infection plays an important role in the genesis of intercapillary glomerulosclerosis.

With the object of limiting the ageing vascular processes considered to be related to disordered lipoid and cholesterol metabolism, attempts have been made to reduce hypercholesterolaemia by a number of investigators, but of special interest are the observations of Morrison and Gonzales (I950) using choline (known to limit experimentallyinduced arteriosclerosis (Steiner, 1938) and fatiy infiltration of the liver (Blumberg, I94I). In 230 cases of coronary occlusion their results showed that of I I 5 cases treated with choline (using choline bicarbonate) for periods of up to three years, only i 4 ( 12 per cent.) died (six of recurrent coronary thrombosis, five of congestive cardiac failure and three of extracardiac causes), whereas in a control group of 1 I 5 not given choline 35 (30 per cent.) died (19 of recurrent coronary thrombosis, ro of congestive cardiac failure and six of extracardiac causes).

In view of the marked increase in vascular ageing processes occurring in diabetes and the fact that raised cholesterol was characteristically present in association with intercapillary glomerulosclerosis, it seems that the benefits of experiments such as those of Steiner and Morrison may indicate a second approach towards the limitation of diabetic vascular complications.

\section{Summary}

Three cases of Kimmelstiel-Wilson syndrome are described. The literature relating to Kimmelstiel-Wilson syndrome and intercapillary glomerulosclerosis is reviewed in relation to the components of the syndrome. Of the two types of intercapillary glomerulosclerosis it is concluded that only the nodular form has any specific relation to diabetes. It is considered that a severe degree of nodular intercapillary glomerulosclerosis will commonly be associated with hypertension, nephrotic syndrome and retinitis. Better control of the diabetes may well reduce the vascular complications and it is suggested that measures which reduce hypercholesterolaemia may reduce the accelerated general vascular ageing process of diabetes and therefore limit the development and/or progress of intercapillary glomerulosclerosis.

Since this article was written a full and authoritative account of the pathological changes occurring in diabetic intercapillary glomerulosclerosis has heen published in 'The Kidney' (Allen, 1952).

\section{Acknowledgments}

I am indebted to Mr. W. E. Wimberger, Medical Superintendent, Hallam Hospital, West Bromwich, for permission to publish the cases, and to Professor Orr, United Birmingham Hospitals, for opportunities to see histological material in his department.

I am indebted to Dr. A Brian Taylor, United Birmingham Hospital, for advice and help in writing this article.

\section{BIBLIOGRAPHY}

ALLEN, A. C. (1952), 'The Kidney,' London, Churchill, +25. ALLEN, A. C. (1941), Arch. of Path., 32, 33.

ALWALL, N, EKELUND, C., and ORAS, L. (1950), Acta. Med. Scand., 136, 5, 359 .

ANSON, L. J. (1938), South Med. F., 31, 1272.

BALLANTYNE, A. J. (1947), Trans. Oph. Soc., 67, 59.

BELL, E. T. (1946), 'Renal Diseases,' London, Kimpton, 395.

BLUMBERG, H., and MCCOLLUM, E. V. (194I), Science, 93. 598.

CROOM, J. H., and SCOTT, G. (I 949), Lancet, i, 555.

DEROW, H. A., ALTSCHULE, M. D., and SCHIESINGER, J. J. (1939), New Eng. F. Med., 221 , 1012.

DOLGER, H. (1947), F.A.M.A., 134, 1289.

FAHR, T. (1942), Virchows Arch., 309, 16.

GAULD, W., STALKER, A. L., and LYALI, A. (1948), B.M.\%. ii, 194 .

(IILLILAND, I. (1951), Ibid., i, 916

GUNTER, W. H. (1941), V'irchows Arch., 307, 380.

GOODOF, I. (1945), Ann. Int. Med., 22, 373. Rep., 71, 43 .

HENDERSON, L., SPRAGUE, R. G., and WAGENER, H. P. (1947), Amer. Э. Med., 3, 131 .

HERBUT, P. A. (1941), Arch. of Path., 31, 501.

HERTZOG, A. J., and HAYFORD, W. D. (1947), Minnesota Med. 30, 3,280 .

HORN, R. C., and SME'TANA, H. (1942), Amer. F. Path., 18, 93.

HUEPER, W. C. (1949), Med. Clin. of N.A., 33, 773.

JOSLIN E. P. (1946) 'The Treatment of Diabetes Mellitus,' 8th Ed., London, H. Kimpton.

KIMMELSTIEL, P., and WILSON, C. (1936), Amer. F. Path., 12,83 .

KIMMELSTIEL, P., and PORTER, W. D. (1948), Nero Eng. F. Med., 238, 876 , 908 . 
LAIPPLY, T., EITZAN, O., and RUTRA, F. R. (1944), Arch. Int. Med., 74, 354

MacCUlluM, W. G. (1934), Bull. Fohn's Hopkins Hospital, 55, 416.

MacMANUS, J. F. A. (1950), 'Medical Diseases of the Kidney,' London, H. Kimpton, 146 .

MARTIN, E., and ALPHONSE, P. (1946), Paris Med., 2, 364.

MAUSER, C. L., ROWE, A. H., and MICHAEL, P. P. E. (1942), Ann. Int. Med., 17, 101 .

MORRISON, L. M., and GONZAI.ES, W. F. (1950), Proc. Soc. Exp. Biol., N.Y., 73, 37 .

NEWBURGER, R. A., and PETERS, J. P. (1939), Arch. Int. Med., $64,1,253$.

POR'TER, W., and WALKER, H. (1941), F.A.M.A., I16, 459. ROOT, H. F., and SHARKEY, T. P. (1936), Ann. Int. Med., 9, 873 .

ROOT, H. F., SINDEN, R. H., and ZANCA, R. (1950), $A m . \mathcal{F}$ Dig. Dis., 17,179 .
SIEGAL, S., and ALLEN, A. (I941), Am. F. M. Sc., 201, 516. 气 SIMON, M. A. (1940), Canad. M.A.F., 43, 525.

SPUHLER, O., and ZOLLINGER, H. (1943), Scweiz. med Wchnschr., 73, $1430,1432$.

SPUHLER, O., and ZOLLINGER, H. (I943), Deutsch. Arch. $\tilde{E}$ Klin. Med., 190, $32 \mathrm{I}$.

STEINER, A. (1938), Proc. Soc. Exp. Biol., N.Y., 39, 41 1 STEINER, A. (1938), Proc. Soc. Exp. Biol., N. Y., 39, 411.
WAITE, J. H., and BEETHAM, W. P. (1935), New Eng. F. Med.
212, 367.

WERNLY, M. (1944), Rer. Med., Suisse Rom., 64, 615. WILSON, J. L., ROOT, H. F., and MARBLE, A. (I951a), Am. . $\frac{\bar{\sigma}}{\overline{6}}$
$M$. Sc., 221, 5, 479.

WILSON, J. L, ROOT, H. F., and MARBLE A. (r95 Ib), Nerه Eng. F. Med., 245, 513.

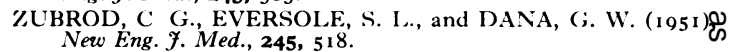

ZUBROD, C. G., EVERSOLE, S. L., and DANA, (;. W. (1952) Bull. Fohn's Hopkins Hospital, 90, 98.

\title{
CLINICAL SECTION
}

\section{CLINICO-PATHOLOGICAL CONFERENCE-No. 19 *}

\author{
Unexplaired Ccma in a Case of Bronchial Carcinoma
}

\section{Clinical History (Dr. Sheila Sherlock)}

A factory sweeper, aged 42 , walked into hospital on February 20, I952, for investigation of glycosuria. His intelligence was low and he gave a poor history. For three weeks he had been tired and thirsty; he had lost his appetite and his weight was falling. He remained at work until one week before admission. On the day of admission he collapsed in the street, but the circumstances of this were uncertain. At no time had he experienced either vomiting or diarrhoea. There were no chest symptoms. His alcohol intake was heavy.

The patient on admission was confused and unable to give an adequate history. The eyes were protruberant; this was thought to be congenital. The patient had a Mongol-gargoyle-like facies, and a high arched palate. The skin was pigmented, but most of this could be removed with soap and water. The tongue and skin were very dry. 'There was oedema of the ankles. 'The pulse was regular, the blood pressure $260 / 160$, and the heart was slightly enlarged to the left, with an apical systolic murmur. 'The fundi oculi

\footnotetext{
*Presented at the Postgraduate Medical School (Hammersmith Hospital) on June I I, I 952. The report was assembled by Dr. Bernard Lennox. The sections were prepared by Mr. J. G. Griffin and the photographs by Mr. E. V. Willmott.
}

were normal, suggesting that the hypertens was of recent origin. The chest examination showed only scattered rhonchi. The liver enlarged, hard and knobbly. 'There was no ascites. The legs showed pustular lesions, probo ably scabies. 'The urine specific gravity was Ior and the urine contained glucose, but no acetone bodies; albumin was absent.

It was difficult to formulate a clinical diagnosis The patient was clearly not in diabetic pre-coma the blood pressure was high, the breathing was normal, the urine contained no acetone and thers was oedema. The clinical picture and urinar $\frac{3}{\mathrm{y}}$. findings were not those of renal failure. Similarly liver failure seemed unlikely. The patient was not jaundiced and there was no ascites. Haemo 3 chromatosis was considered, because of the hepa tomegaly, glycosuria and skin pigmentation, but? as this latter was an artefact, this diagnosis als was discarded. The large, irregular liver an general falling off of health suggested a neoplasn and the peculiar mental state might have been related to cerebral metastases. Multiple diagnoses were probable.

'The chest X-ray showed a small cannon-ba将 lesion in the left mid-zone of the lung, lying posteriorly. This could have been a primare bronchial neoplasm of peripheral type or a secon:dary deposit from a tumour elsewhere. The vertebral X-rays showed osteoporosis. 